\title{
Computerised Design and Simulation of Meshing and Contact of Formate Hypoid Gears Generated with a Duplex Helical Method
}

\author{
Yu Zhang ${ }^{1}$ - Hongzhi Yan ${ }^{1, *}$ - Tao Zeng 1,2 \\ ${ }^{1}$ Central South University, State Key Laboratory of High-Performance Complex Manufacturing, China \\ 2 Changsha Haliang Kaishuai Precision Machinery Co., China
}

The duplex helical method has higher machining efficiency for face-milling spiral bevel and hypoid gears. An accurate and practical approach for calculating the basic machine-tool settings of spiral bevel and hypoid gears manufactured with the duplex helical method is proposed in the present work. The gear tooth surface vector functions and curvature parameters based on basic machine, and head-cutter settings are calculated. Two types of curvature parameters for pinion tooth surfaces are obtained by utilizing the conjugation of gear and pinion tooth surfaces, and the conjugation of pinion tooth surfaces and pinion head-cutter surfaces at the reference point. Next, the basic machine settings for generating pinions in accordance with the two types of curvature parameters for pinion tooth surfaces are determined. Finally, a numerical examples using the duplex helical method are performed and validated by comparing with experimental results. New hypoid gear software has been developed using the new approach.

Keywords: duplex helical method, spiral bevel and hypoid gears, face milling, basic machine settings, curvature parameter

Highlights
- A new exact calculation approach for basic machine-tool settings is proposed.
- $\quad$ Three reference points are used to determine the optimal machine settings.
- $\quad$ Hypoid gear design software has been developed using the new approach.

\section{INTRODUCTION}

Spiral bevel and hypoid gear drives are widely employed as transmission elements in vehicles, aircrafts, ships, and other gear reducers. There are currently two main methods of producing spiral bevel [1] and hypoid gears [2] in the production environment: the single indexing method referred to as "face milling" [3], and the continuous indexing method referred to as "face hobbing" [4]. In both face milling and face hobbing, the gear may be cut using either a generating method or a non-generating (formate) method [4]. However, the pinion of a pair of mating hypoid gears is always cut using the generating method to satisfy the required contact characteristics. The non-generating method offers higher productivity than the generating method because the generating roll is eliminated in the former method. The manufacturing of face-milled spiral bevel and hypoid gear sets can be accomplished by using the five-cut process [5] or by using the duplex helical method or completing process [6]. The five-cut process consists of five independent operations: two operations to finish the gear, and three operations to finish the pinion [5].

Generalized theory and application of bevel and hypoid gears generated by the five-cut process have been comprehensively presented by several gear scientists [7] to [9]. The generating method and the formate method of the five-cut process for face-milled spiral bevel and hypoid gears have been described in detail in [10] and [11]. Litvin et al. developed the principle and the calculation processes for the fivecut process independently in a manner that is different from Gleason's technology described in [12] and [13]. Astoul et al. [14] presented a new design method of spiral bevel gears based on an optimization process to reduce their quasi-static transmission error. Cao et al. [15] proposed a new method to design pinion machine tool-settings for spiral bevel gears by controlling contact path and transmission errors based on the satisfaction of contact the condition of three given control points on the tooth surface. Su et al. [16] proposed a new approach to designing and implementing a seventh-order polynomial function of transmission error for spiral bevel gears in order to reduce the running vibration and noise of gear drive and improve the loaded distribution of the tooth.

Computerised design, manufacturing and simulation of meshing, and contact stress analysis of spiral bevel and hypoid gears are the subjects of research performed by many scientists [17] and [18]. Lin et al. [19] developed a numerical tooth contact 
analysis technique for simulating the single flank test of the gear geometry data measured on a gear measuring centre. Fan developed a new generalized tooth surface generation algorithm and a tooth contact analysis (TCA) approach [3], and presented a new generic model of generating spiral bevel and hypoid gears, this model is applicable to both face-milling and face-hobbing processes based on the universal motion concept (UMC) [20]. Simon [21] presented a new method for computer-aided tooth contact analysis in mismatched spiral bevel gears. In addition, Tamizharasan and Senthil Kumar [22] proposed an attempt to minimize flank wear of uncoated carbide inserts while machining AISI 1045 steel by finite element analysis, this simulation method can provide a reference for the finite element simulation of spiral bevel and hypoid gears.

The principle and machining character of the duplex helical method are evidently different from that of the five-cut process. The cutters used for the duplex helical method have alternate (inside and outside) blades. The head cutter is mounted on the cradle that has a helical motion with respect to the gear blank; the work spindle is mounted on the sliding base that have an infeed motion with the rotation of the cradle. When a single cutter is used in one operation, both sides of the tooth slot are finished from a solid blank during machining. The advantages of using this method are as follow [6]: (1) the higher machining efficiency, (2) the assurance of uniform gears and, therefore, greater accuracy, since the size of the teeth is not dependent upon the manual controls of the operator, (3) the reduction of spoilage by manual mistake, and (4) the smoother bending of the bottom and sides of the teeth.

The duplex helical method was invented several decades earlier by Gleason [5], although only some formulas and calculating instructions for the duplex helical method for hypoid gears have been published. However, as Gleason's technology is confidential, the public has little knowledge of its principle and method in detail thus far. To the best knowledge of the authors of this paper, Gonzalez-Perez et al. dealt with conversion of the specific machine-tool settings of a given hypoid generator to the neutral machinetool settings and adjustment the contact pattern by considering parabolic profiles on the blades of the head-cutter [23]. Fong proposed a mathematical model of a universal hypoid generator and applied it to simulate virtually all primary spiral bevel and hypoid cutting methods, including the duplex helical method, the supplemental kinematic flank correction motions, such as modified generating roll ratio, helical motion, and cutter tilt were included in the proposed mathematical model [24].

In this paper, the authors present a new method that is used to accurately calculate basic machine-tool settings for formate hypoid gears. The new method aims to: (i) present the generalized theory of the duplex helical method in detail, (ii) obtain the desired meshing quality for the duplex helical method by using precise calculation.

\section{CALCULATION OF BASIC MACHINE-TOOL SETTINGS FOR GENERATING GEAR}

The coordinate system $S_{m}\left\{X_{m}, Y_{m}, Z_{m}\right\}$ is rigidly connected to the cutting machine (Fig. 1). The top, bottom (A-A) and right (B-B) of Fig. 1 are the machine front view, the machine bottom view and the side view (the projection of the head cutter). The cradle rotates about the $Y_{m}$ axis; the $\mathbf{p}$ axis and $\mathrm{g}$ axis are projections of gear and pinion axes in the $X_{m} O_{m} Y_{m}$ plane, respectively. The points $\mathrm{M}, \mathrm{M}_{1}$ and $\mathrm{O}_{0}$ are the reference points of the tooth surface and the projection of $\mathrm{M}$ on the cutting edge and the centre of the head cutter, respectively. $\mathrm{O}_{2}$ is the cross point of the gear, and $\mathrm{O}_{m}$ is the machine centre. The process for calculation of the machine-tool settings of the duplex helical method is the same as that of the fivecut process, details of which can be found in [10].

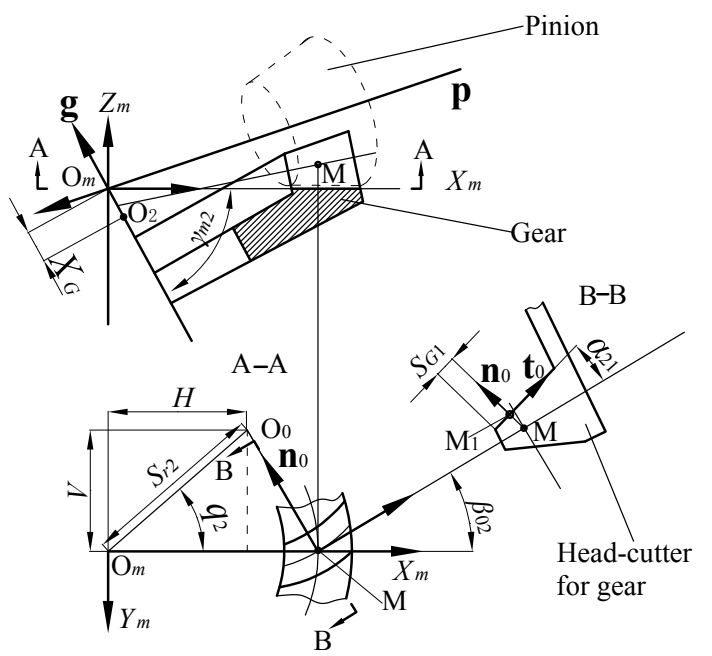

Fig. 1. Coordinate system applied for gear generation

The unit vectors of the $Y_{m}$ axis, $\mathbf{g}$ axis, and $\mathbf{p}$ axis can be represented in the coordinate system $S_{m}$ by the following equations:

$$
\mathbf{e}=\left[\begin{array}{lll}
0 & 1 & 0
\end{array}\right]
$$




$$
\begin{gathered}
\mathbf{g}=\left[\begin{array}{lll}
-\cos \gamma_{m 2} & 0 & \sin \gamma_{m 2}
\end{array}\right], \\
\mathbf{p}=\left[\begin{array}{ccc}
-\cos \left(\Sigma-\gamma_{m 2}\right) & 0 & -\sin \left(\Sigma-\gamma_{m 2}\right)
\end{array}\right] .
\end{gathered}
$$

The unit normal $\mathbf{n}_{0}$, the unit vector $\mathbf{t}_{0}$ and the position vector $\mathbf{a}_{0}$ of a point on the outside blade edge of the gear to the head cutter-generating surface (drive or convex side) can be defined in the coordinate system $S_{m}$ by the following equations:

$$
\begin{gathered}
\mathbf{n}_{0}=\left[\begin{array}{lll}
-\cos \alpha_{21} \sin \beta_{02} & -\cos \alpha_{21} \cos \beta_{02} & -\sin \alpha_{21}
\end{array}\right],(4) \\
\mathbf{t}_{0}=\left[\begin{array}{lll}
-\sin \alpha_{21} \sin \beta_{02} & -\sin \alpha_{21} \cos \beta_{02} & \cos \alpha_{21}
\end{array}\right], \\
\mathbf{a}_{0}(u)=u \mathbf{t}_{0}+\left[\begin{array}{c}
H-X_{G} \cos \gamma_{m 2}+r_{c G 1} \sin \beta_{02} \\
r_{c G 1} \cos \beta_{02}-V \\
X_{G} \sin \gamma_{m 2}
\end{array}\right]
\end{gathered}
$$

Here, $u$ is a profile parameter. The position vector of point $\mathrm{M}_{1}$ on the blade edge can be represented by $\mathbf{a}_{0}\left(s_{G 1}\right)$ when $u$ is equal to $s_{G 1}$ as denoted in Fig. 1.

\section{CALCULATION OF BASIC MACHINE-TOOL SETTINGS FOR GENERATING PINION}

\subsection{Calculation of Pinion Curvature Parameters Based on Gear Tooth Surfaces}

To facilitate the description of this paper, the following definitions are made: $\Sigma_{2}$ is the gear tooth surface. $\Sigma_{1}$ is the pinion tooth surface. $\Sigma_{g}$ is the gear head-cutter surface or the generating tooth surface of the gear. $\Sigma_{p}$ is the pinion head-cutter surface or the generating tooth surface of the pinion. $M_{1}$ is the reference point of the drive side. $\mathrm{M}_{2}$ is the reference point of the coast side. The pinion is the driving wheel and left hand, gear is the driven wheel and right hand. The driving side is the convex side of gear, the concave side of pinion, the inside blades of the gear head-cutter and the outside blades of the pinion head-cutter. The coast side is the concave side of the gear, the convex side of the pinion, the outside blades of the gear head-cutter and the inside blades of the pinion head-cutter.

The formate-cut gear tooth surface is a copy of the surface of the head-cutter, which is a surface of revolution. Therefore, the vectors $\mathbf{a}_{0}\left(s_{G 1}\right), \mathbf{t}_{0}, \mathbf{n}_{0}$ of generating gear are the same as the vectors of the gear tooth surface.

A rotation angle $\theta_{1}$ of the gear about the g-axis is necessary for tangency at $\mathrm{M}_{1}$ of the gear and pinion tooth surfaces $\Sigma_{2}$ and $\Sigma_{1}$. The position vector of the reference point $\left(\mathrm{M}_{1}\right) \mathbf{r}_{1 d r}\left(\theta_{1}\right)$, the unit normal $\mathbf{n}_{1 d r}\left(\theta_{1}\right)$ and the unit vector $\mathbf{t}_{1 d r}\left(\theta_{1}\right)$ in the pinion tooth surface can be represented as:

$$
\begin{gathered}
\mathbf{r}_{1 d r}\left(\theta_{1}\right)=E \mathbf{e}+\mathbf{a}_{1}\left(\theta_{1}\right), \\
\mathbf{a}_{1}\left(\theta_{1}\right)=\mathbf{a}_{0}\left(s_{G 1}\right) \cdot \mathbf{R}\left[\mathbf{g}, \theta_{1}\right], \\
\mathbf{n}_{1 d r}\left(\theta_{1}\right)=\mathbf{n}_{0} \cdot \mathbf{R}\left[\mathbf{g}, \theta_{1}\right], \\
\mathbf{t}_{1 d r}\left(\theta_{1}\right)=\mathbf{t}_{0} \cdot \mathbf{R}\left[\mathbf{g}, \theta_{1}\right] .
\end{gathered}
$$

Here, $\mathbf{R}\left[\mathbf{g}, \theta_{1}\right]$ is a transformation matrix that denotes the rotation angle $\theta_{1}$ about the vector $\mathbf{g}$. Unit vector $\mathbf{e}$ is given in Eq. (1).

The vectors $\mathbf{a}_{1}\left(\theta_{1}\right), \mathbf{e}, \mathbf{g}, \mathbf{p}$ and are determined in the coordinate system $S_{2}\left\{\mathbf{t}_{1 d r} \times \mathbf{n}_{1 d r}, \mathbf{t}_{1 d r}, \mathbf{n}_{1 d r}\right\}$ by the following equations:

$$
\begin{aligned}
\mathbf{a}_{2}\left(\theta_{1}\right) & =\mathbf{a}_{1}\left(\theta_{1}\right) \cdot \mathbf{M}_{2 m}, \\
\mathbf{e}_{2} & =\mathbf{e} \cdot \mathbf{M}_{2 m}, \\
\mathbf{g}_{2} & =\mathbf{g} \cdot \mathbf{M}_{2 m}, \\
\mathbf{p}_{2} & =\mathbf{p} \cdot \mathbf{M}_{2 m} .
\end{aligned}
$$

Here, matrix $\mathbf{M}_{2 m}$ represents the coordinate transformation from $S_{m}$ to $S_{2}$.

The meshing equation for hypoid gears can be represented as:

$$
f_{12}\left(\theta_{1}\right)=\mathbf{v}_{12}\left(\theta_{1}\right) \cdot \mathbf{n}_{1 d r}=0 .
$$

Here, the relative velocity $\mathbf{v}_{12}$ of the gear and pinion tooth surfaces $\Sigma_{2}$ and $\Sigma_{1}$ at $\mathrm{M}_{1}$ can be obtained from the abovementioned vectors. The parameter $\theta_{1}^{*}$ can be obtained by solving Eq. (15). The related parameters can be obtained by inserting the value of $\theta_{1}^{*}$ into Eqs. (7) to (11).

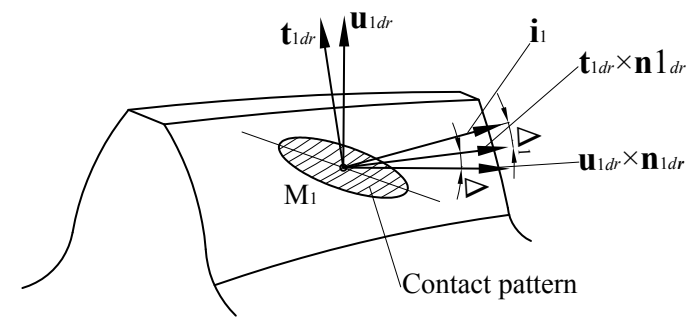

Fig. 2. The principal directions on the tangent plane

Fig. 2 shows the principal directions on the tangent plane at the reference point. The so-called first principal direction denotes the direction of maximum curvature of tooth surface; the second principal direction denotes the direction of minimum curvature of the tooth surface. In general, the two directions are perpendicular to each other. The first or second principal curvature or torsion is the curvature or 
torsion in the corresponding first or second principal direction.

The first principal curvature $A_{2}$ in the gear tooth surface is represented as:

$$
A_{2}=\frac{1}{R_{n 1}}
$$

Here, $R_{n 1}$ denotes the radius of curvature of the inside blade of the gear head-cutter. The first principal torsion $B_{2}$ and the second principal curvature $C_{2}$ of the gear tooth surface are equal to 0 .

According to the Baxter method [25], the induced normal curvatures $\Delta A, \Delta C$, and torsion $\Delta C$ of the two conjugate tooth surfaces $\left(\Sigma_{2}\right.$ and $\left.\Sigma_{1}\right)$ at $\mathrm{M}_{1}$ can be represented as:

$$
\begin{gathered}
\theta_{v}=\theta_{v}\left(\theta_{1}^{*}\right), \\
\Delta C=\Delta C\left(\theta_{1}^{*}\right), \\
\Delta A=\Delta C \tan ^{2} \theta_{v}, \\
\Delta B=-\Delta C \tan \theta_{v} .
\end{gathered}
$$

Here, the $\theta_{v}$ is the direction angle of the contact line that is formed between the tooth surfaces $\Sigma_{2}$ and $\Sigma_{1}, \theta_{v}$ and $\Delta C$ can be obtained from the relative angular velocity $\boldsymbol{\omega}_{12}$, the relative velocity $\mathbf{v}_{12}$, and the relative acceleration $\mathbf{a}_{12}$ of the gear and pinion tooth surfaces $\Sigma_{2}$ and $\Sigma_{1}$ at $\mathrm{M}_{1}$.

The first principal curvature $A_{0}$, the first principal torsion $B_{0}$, and the second principal curvature $C_{0}$ of the pinion tooth surface (drive side) at $\mathrm{M}_{1}$ for the two principal directions of the gear tooth surface (Fig. 2) can be represented as:

$$
\left\{\begin{array}{l}
A_{0}=A_{2}-\Delta A \\
B_{0}=-\Delta B \\
C_{0}=-\Delta C
\end{array} .\right.
$$

Based on the generalised Euler and Bertrand formulas [13], the curvature parameters of the pinion tooth surface (drive side), along the two principal directions of the pinion tooth surface, can be represented as:

$$
\begin{gathered}
A_{1 d r}=A_{0} \cos ^{2} \Delta-2 \mathrm{~B}_{0} \sin \Delta \cos \Delta+C_{0} \sin ^{2} \Delta . \\
C_{1 d r}=C_{0} \cos ^{2} \Delta+2 \mathrm{~B}_{0} \sin \Delta \cos \Delta+A_{0} \sin ^{2} \Delta, \\
B_{1 d r}=B_{0}\left(\cos ^{2} \Delta-\sin ^{2} \Delta\right)+\left(A_{0}-C_{0}\right) \sin \Delta \cos \Delta .
\end{gathered}
$$

Here, $\Delta$ is the angle between the first principal direction of the gear tooth surface and the pinion tooth surface on the tangent plane (Fig. 2). $\mathbf{u}_{1 d r}$ can be represented as:

$$
\mathbf{u}_{1 d r}=\left(\mathbf{t}_{1 d r} \times \mathbf{n}_{1 d r}\right) \sin \Delta+\mathbf{t}_{1 d r} \cos \Delta .
$$

In the same way, all of the related parameters and vectors (including the curvature parameters $A_{1 c o}, B_{1 c o}$, $C_{1 c o}$ ) of the coast side of the pinion tooth surface can be obtained.

\subsection{Calculation of Pinion Curvature Parameters Based on Pinion-Generating Surfaces}

The configuration in Fig. 3 is the same as that in Fig. 1. The coordinate system $S_{m}\left\{X_{m}, Y_{m}, Z_{m}\right\}$ is rigidly connected to the cutting machine (Fig. 3). The top (AA), bottom and middle of Fig. 3 are the machine front view, top view and side view (projection of the head cutter), respectively. The cradle rotates about the $\mathbf{G}$ axis. The $\mathbf{p}$ axis is the projection of the pinion spindle in the $X_{m} O_{m} Y_{m}$ plane. The points $\mathrm{O}_{m}, \mathrm{O}_{0}$ and $\mathrm{O}_{1}$ are the machine centre, the centre of the head cutter, and the cross point of the pinion, respectively.

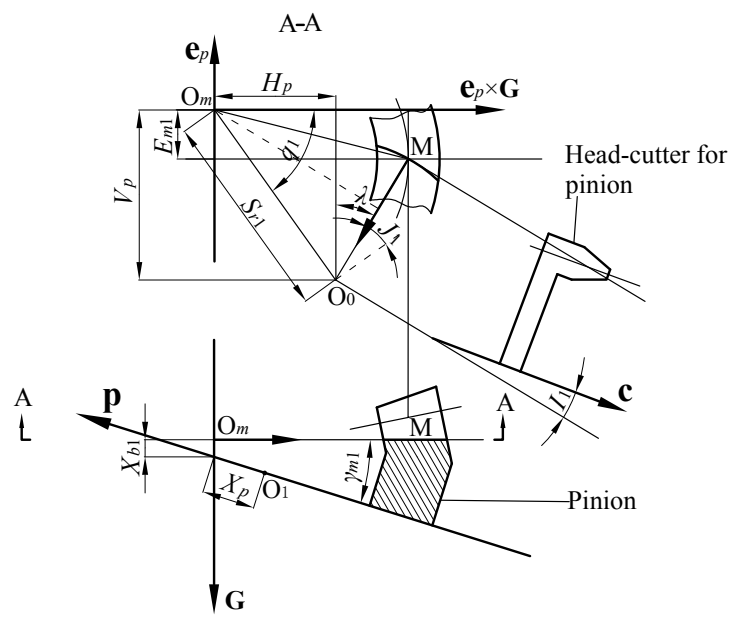

Fig. 3. Coordinate system applied for pinion generation

The manufacturing coordinate system of the gears and pinions and the installation coordinate system of the hypoid gear set are represented in the coordinate system $S_{m}$. Taking backlash and other factors into account, for tangency at the reference point $\mathrm{M}_{2}$ of the gear and pinion tooth surfaces $\Sigma_{2}$ and $\Sigma_{1}$, the position vector $\mathbf{r}_{2}$ of the reference point, the unit normal $\mathbf{n}_{2}$ and the unit vector $\mathbf{u}_{2}$ of the coast side of the pinion tooth surface at the reference point $\mathrm{M}_{2}$ can be represented as:

$$
\begin{aligned}
& \mathbf{r}_{2}=\mathbf{r}_{1 c o} \cdot \mathbf{R}\left[\mathbf{p}, \theta_{2}\right], \\
& \mathbf{n}_{2}=\mathbf{n}_{1 c o} \cdot \mathbf{R}\left[\mathbf{p}, \theta_{2}\right], \\
& \mathbf{u}_{2}=\mathbf{u}_{1 c o} \cdot \mathbf{R}\left[\mathbf{p}, \theta_{2}\right] .
\end{aligned}
$$


Here, the matrix $\mathbf{R}\left[\mathbf{p}, \theta_{2}\right]$ is a transformation matrix that denotes the rotation angle $\theta_{2}$ (known parameter) about the vector $\mathbf{p}$.

The pinion cradle spindle $\mathbf{G}$ does not always coincide with the $Y_{m}$ axis (Fig. 3), and it can be represented in the coordinate system $S_{m}$ as:

$$
\mathbf{G}=\mathbf{G}\left(\alpha_{G 1}, \gamma_{m 1}\right) \text {. }
$$

The position vector of the reference point $\mathrm{M}_{1}$ and the unit vector of the blank offset direction of the generating gear and the pinion can be represented in the coordinate system $S_{m}$ as:

$$
\begin{gathered}
\mathbf{a}_{p 1}\left(X_{p}, E_{m 1}\right)=\mathbf{r}_{1 d r}+X_{p} \mathbf{p}+E_{m 1} \mathbf{e}_{p}, \\
\mathbf{e}_{p}=\mathbf{e}_{p}\left(\alpha_{G 1}, \gamma_{m 1}\right) .
\end{gathered}
$$

The relative velocity $\mathbf{v}_{p 1}$ of the generating gear and pinion tooth surfaces $\Sigma_{p}$ and $\Sigma_{1}$ at $\mathrm{M}_{1}$ can be obtained using the vectors $\mathbf{G}, \mathbf{a}_{p 1}, \mathbf{p}, \mathbf{r}_{1 d r}$. This can be represented as:

$$
\mathbf{v}_{p 1}=\mathbf{v}_{p 1}\left(\alpha_{G 1}, \gamma_{m 1}, X_{p}, E_{m 1}, H_{l}, R_{a 1}\right) .
$$

Here, $\alpha_{G 1}, \gamma_{m 1}, X_{p}, E_{m 1}, H_{l}, R_{a 1}$, are unknown parameters.

The meshing equation for the generating gear and pinion tooth surfaces at $\mathrm{M}_{1}$ may be represented in the coordinate system $S_{m}$ as:

$$
f_{p 1}=f_{p 1}\left(\alpha_{G 1}, \gamma_{m 1}, X_{p}, E_{m 1}, H_{l}, R_{a 1}\right)=\mathbf{v}_{p 1} \cdot \mathbf{n}_{1 d r}=0 .
$$

Based on Eq. (33), $R_{a 1}$ can be obtained using the following equation:

$$
R_{a 1}=f_{p 1}\left(\alpha_{G 1}, \gamma_{m 1}, X_{p}, E_{m 1}, H_{l}\right) .
$$

To perform tangency at $\mathrm{M}_{1}$ or $\mathrm{M}_{2}$ of the pinion tooth surface $\Sigma_{1}$ and the pinion head-cutter surface $\Sigma_{p}$, a rotation angle $\theta_{3}$ of the pinion about the $\mathbf{p}$ axis and a rotation angle $\theta_{3} / R_{a 1}$ of generating gear about the $\mathbf{G}$ axis are necessary (Fig. 3). The position vector from the reference point to the crossing point $\mathbf{r}_{4}$, the position vector from the reference point to the machine centre $\mathbf{a}_{4}$, the unit normal $\mathbf{n}_{4}$ and the unit vector $\mathbf{u}_{4}$ of the coast side of the pinion tooth surface at the reference point $\mathrm{M}_{2}$ can be represented as:

$$
\begin{gathered}
\mathbf{r}_{4}=\mathbf{r}_{2} \cdot \mathbf{R}\left[\mathbf{p}, \theta_{3}\right], \\
\mathbf{n}_{4}=\mathbf{n}_{2} \cdot \mathbf{R}\left[\mathbf{p}, \theta_{3}\right], \\
\mathbf{u}_{4}=\mathbf{u}_{2} \cdot \mathbf{R}\left[\mathbf{p}, \theta_{3}\right], \\
\mathbf{a}_{4}=\mathbf{r}_{4}+X_{p} \mathbf{p}+E_{m 1} \mathbf{e}_{p} .
\end{gathered}
$$

Here, matrix $\mathbf{R}\left[\mathbf{p}, \theta_{3}\right]$ is a transformation matrix that denotes the rotation angle $\theta_{3}$ (unknown parameter) about the vector $\mathbf{p}$.

Based on Eqs. (33) and (34), $\theta_{3}^{*}$ can be obtained by solving the meshing equation for the coast sides of the generating gear and pinion tooth surfaces at $\mathrm{M}_{2}$. The angle $\theta_{3}^{*}$ can be obtained using the following equation:

$$
\theta_{3}^{*}=\theta_{3}^{*}\left(\alpha_{G 1}, \gamma_{m 1}, X_{p}, E_{m 1}, H_{l}\right) .
$$

Given a rotation angle $\theta_{3}^{*} / R_{a 1}$ of the piniongenerating surface about the G-axis, the position vector $\mathbf{a}_{6}$ and the unit normal $\mathbf{n}_{6}$ can be represented as:

$$
\begin{gathered}
\mathbf{a}_{6}\left(\alpha_{G 1}, \gamma_{m 1}, X_{p}, E_{m 1}, H_{l}\right)= \\
=H_{l} \frac{\theta_{3}^{*}}{R_{a 1}} \mathbf{G}+\mathbf{a}_{4} \cdot \mathbf{R}\left[\mathbf{G}, \frac{\theta_{3}^{*}}{R_{a 1}}\right], \\
\mathbf{n}_{6}\left(\alpha_{G 1}, \gamma_{m 1}, X_{p}, E_{m 1}, H_{l}\right)=\mathbf{n}_{4} \cdot \mathbf{R}\left[\mathbf{G}, \frac{\theta_{3}^{*}}{R_{a 1}}\right] .
\end{gathered}
$$

The unit vector of the pinion head-cutter axis can be obtained using the vectors $\mathbf{a}_{6}, \mathbf{n}_{6}, \mathbf{a}_{p 1}, \mathbf{n}_{1}$, and can be represented as:

$$
\mathbf{c}=\mathbf{c}\left(\alpha_{G 1}, \gamma_{m 1}, X_{p}, E_{m 1}, H_{l}, r_{n 1}, r_{n 2}\right) .
$$

The unit vector of the first principal directions of the pinion-generating surface at $\mathrm{M}_{1}$ can be represented as:

$$
\mathbf{i}_{1}=\frac{\mathbf{c} \times \mathbf{n}_{1 d r}}{\left|\mathbf{c} \times \mathbf{n}_{1 d r}\right|} .
$$

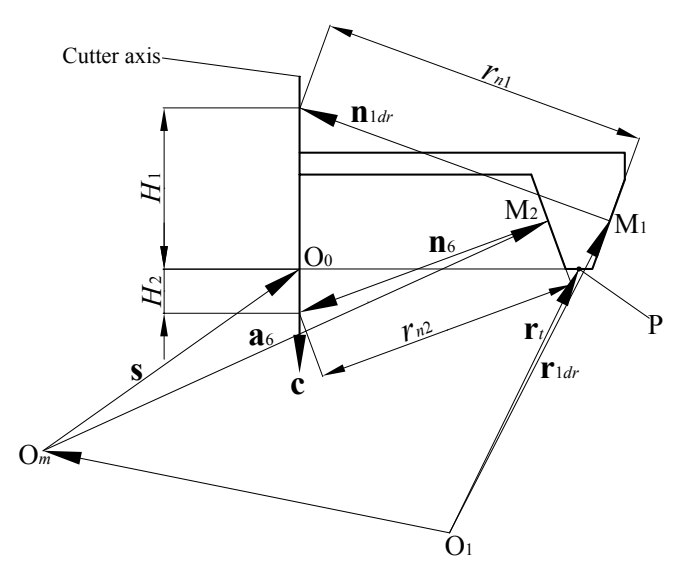

Fig. 4. Projection of pinion head-cutter in the coordinate system $S_{m}$ 
As in Eqs. (11) to (14), the parameters and vectors of the gear and pinion tooth surfaces are replaced by the parameters and vectors of the pinion-generating surface and the pinion tooth surface. Thus, the vectors $\mathbf{a}_{3}, \mathbf{e}_{3}, \mathbf{G}_{3}$ and $\mathbf{p}_{3}$ are obtained in the coordinate system $S_{1}\left\{\mathbf{i}_{1}, \mathbf{n}_{1} \times \mathbf{i}_{1}, \mathbf{n}_{1}\right\}$ from the vectors $\mathbf{a}_{p 1}, \mathbf{e}_{p}, \mathbf{G}, \mathbf{p}$. Relative angular velocity $\boldsymbol{\omega}_{p 1}$, relative velocity $\mathbf{v}_{p 1}$, relative acceleration $\mathbf{a}_{p 1}$ of generating gear and pinion can be obtained from the abovementioned vectors.

The first principal curvature of the piniongenerating surface are represented as:

$$
A_{p d r}=\frac{1}{r_{n 1}}
$$

The first principal torsion $B_{p d r}$ and the second principal curvature $C_{p d r}$ of the pinion-generating surface are equal to 0 . As in Eqs. (17) to (21), the curvature parameters of the pinion tooth surface, along the principal directions of the pinion-generating surface can be obtained.

The angle $\Delta_{1}$ that is formed between the first principal directions of the pinion-generating surface and the pinion tooth surface on the tangent plane can be represented as:

$$
\sin \Delta_{1}=\mathbf{u}_{1} \cdot \mathbf{i}_{1} .
$$

As in Eqs. (22) to (24), the curvature parameters $A_{1 d r}^{\prime}, B_{1 d r}^{\prime}, C_{1 d r}^{\prime}$ of the pinion tooth surface, along the principal directions of the pinion tooth surface, can be obtained using the generalised Euler and Bertrand formulas.

In the same way, all of the related parameters and vectors (including the curvature parameters $\left.A_{1 c o}^{\prime}, B_{1 c o}^{\prime}, C_{1 c o}^{\prime}\right)$ of the coast side of the pinion tooth surface can be obtained.

\subsection{Determination of Basic Machine-Tool Settings for Generating the Pinion}

The theoretical outside and inside blade angles for the pinion can be represented as: (see Fig. 4)

$$
\begin{aligned}
& \sin \alpha_{b 1}=-\mathbf{c} \cdot \mathbf{n}_{1 d r}, \\
& \sin \alpha_{b 2}=-\mathbf{c} \cdot \mathbf{n}_{6} .
\end{aligned}
$$

Theoretically, the curvature parameters of the pinion tooth surfaces along the principal directions of the pinion tooth surface should be the same as that determined by the two abovementioned methods; the theoretical outside and inside blade angles for the pinion should also be equal to the actual blade angles of the head-cutter for the generating pinion. Therefore, the seven equations can be written as follows:

$$
\left\{\begin{array}{l}
f_{b}^{2} A_{1 d r}^{\prime}+A_{1 c o}^{\prime}=f_{b}^{2} A_{1 d r}+A_{1 c o} \\
B_{1 d r}^{\prime}=B_{1 d r} \\
C_{1 d r}^{\prime}=C_{1 d r} \\
B_{1 c o}^{\prime}=B_{1 c o} \\
C_{1 c o}^{\prime}=C_{1 c o} \\
\alpha_{b 1}=\alpha_{11} \\
\alpha_{b 2}=\alpha_{12}
\end{array} .\right.
$$

Here, $f_{b}$ denotes the tooth-bearing length unbalancing factor. The seven unknown parameters $\left(\alpha_{G 1}, \gamma_{m 1}, X_{p}, E_{m 1}, H_{l}, r_{n 1}, r_{n 2}\right)$ can be obtained by solving Eq. (48).

The position vector of the pinion head-cutter generating surface at the blade tip midpoint $\mathrm{P}$ can be represented as:

$$
\mathbf{r}_{t}=h_{f m 1} \mathbf{c}+0.5\left(\mathbf{r}_{1 d r}+\mathbf{r}_{2}\right) .
$$

Here, $h_{f m 1}$ denotes the pinion mean dedendum in the hypoid gear dimensions.

The position vector of the pinion head-cutter centre $\mathrm{O}_{0}$ can be represented as:

$$
\begin{gathered}
\mathbf{s}=r_{n 1} \mathbf{n}_{1 d r}+\mathbf{r}_{1 d r}+H_{1} \mathbf{c}-X_{p} \mathbf{p}-E_{m 1} \mathbf{e}_{p}, \\
H_{1}=\mathbf{c} \cdot\left(\mathbf{r}_{t}-r_{n 1} \mathbf{n}_{1 d r}-\mathbf{r}_{1 d r}\right) .
\end{gathered}
$$

Here, $H_{1}$ denotes the projection distance of $\mathrm{M}_{1}$ on the pinion head-cutter axis.

A rotation angle $\theta_{4}$ of the pinion-generating surface about the $\mathbf{G}$ axis is necessary for meshing the contact of the pinion-generating surface and the tooth surface at $\mathrm{P}$. The value of $\theta_{4}^{*}$ can be obtained by solving the meshing equation.

The root angle of the pinion $\delta_{r}$ can be represented as:

$$
\sin \delta_{r}=\mathbf{p} \cdot \mathbf{n}_{p m}\left(\theta_{4}^{*}\right) .
$$

Here, $\mathbf{n}_{p m}\left(\theta_{4}^{*}\right)$ denotes the unit normal vector after a rotation angle of the pinion-generating surface about the $\mathbf{G}$ axis $\theta_{4}^{*}$.

Generally, $\delta_{r}$ is not equal to the root angle $\delta_{f 1}$ of the hypoid gears' blank dimensions. Therefore, the resulting new mean dedendum $b_{m 1}$ of the pinion is different from the mean dedendum $h_{f m 1}$ of the hypoid gears' blank dimensions. Using the modified mean dedendum $b_{m 1}$, the vectors $\mathbf{r}_{t}, \mathbf{s}$ and $\mathrm{H}_{1}$ should be recalculated.

The outside and inside cutter point radii for the pinion can be obtained as follows:

$$
r_{c p 1}=\frac{r_{n 1}}{\cos \alpha_{b 1}}-H_{1} \tan \alpha_{b 1},
$$




$$
r_{c p 2}=\frac{r_{n 2}}{\cos \alpha_{b 2}}-H_{2} \tan \alpha_{b 2} .
$$

After a rotation angle $\theta_{4}^{*}$ of the pinion-generating surface about the $\mathbf{G}$ axis, the position vector of the pinion head-cutter centre and the unit vector of the pinion head-cutter axis $\mathbf{c}_{1}$ can be redefined as:

$$
\begin{gathered}
\mathbf{s}_{x}=\mathbf{s} \cdot \mathbf{R}\left[\mathbf{G}, \theta_{4}^{*}\right]+H_{l} \theta_{4}^{*} \mathbf{G}, \\
\mathbf{c}_{1}=\mathbf{c} \cdot \mathbf{R}\left[\mathbf{G}, \theta_{4}^{*}\right] .
\end{gathered}
$$

The rest of the basic machine settings for the pinion can be obtained as follow:

$$
\begin{gathered}
X_{b 1}=-\mathbf{s}_{x} \cdot \mathbf{G}, \\
H_{p}=\mathbf{s}_{x} \cdot\left(\mathbf{e}_{p} \times \mathbf{G}\right), \\
V_{p}=-\mathbf{s}_{x} \cdot \mathbf{e}_{p}, \\
\sin I_{1}=|\mathbf{c} \times \mathbf{G}| .
\end{gathered}
$$

\section{NUMERICAL EXAMPLE}

In this section, a hypoid gear design software based on the abovementioned calculation strategy for basic machine-tool settings was developed; the software development flow chart is shown in Fig. 5.

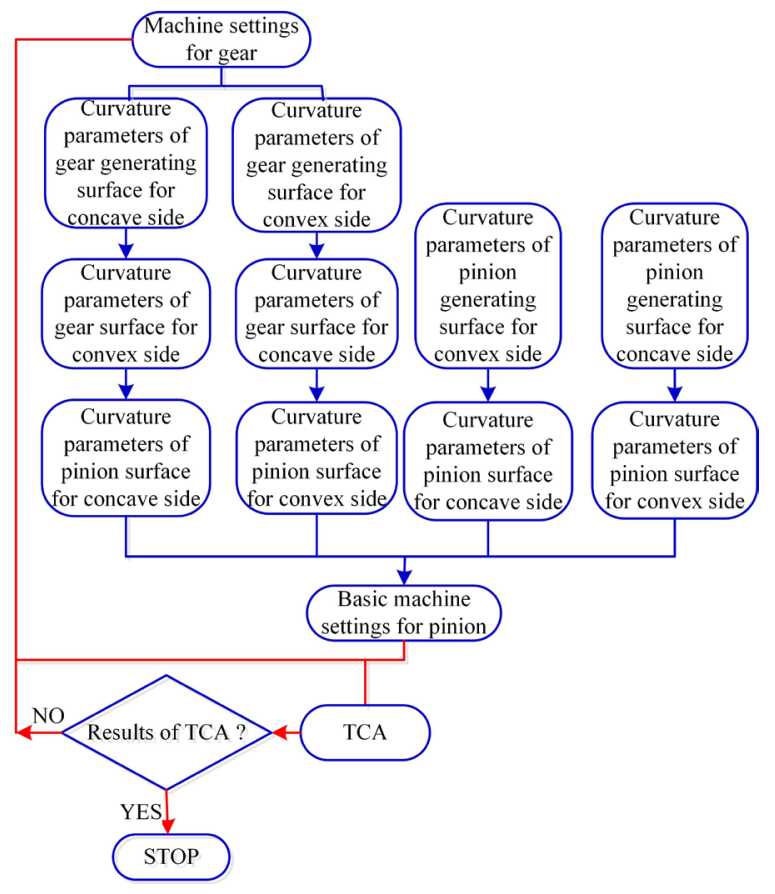

Fig. 5. Spiral bevel and hypoid gear design software development flow chart
The theoretical analysis is performed based on a hypoid gear set generated by using the duplex

\begin{tabular}{|c|c|c|}
\hline Applied settings & Pinion & Gear \\
\hline Radial distance [mm] & 114.2545 & 117.4921 \\
\hline Tilt angle $\left[^{\circ}\right]$ & 15.7363 & 0.0000 \\
\hline Swivel angle $\left[^{\circ}\right]$ & -31.6295 & $0.0000^{\circ}$ \\
\hline Blank offset [mm] & 25.0224 & 0.0000 \\
\hline Machine root angle $\left[{ }^{\circ}\right]$ & -9.0996 & 70.2509 \\
\hline Machine centre to cross point [mm] & 0.3431 & 9.6518 \\
\hline Sliding base [mm] & 23.8256 & 0.0000 \\
\hline Ratio of roll & 5.9651 & 0.0000 \\
\hline Cradle angle $\left[^{\circ}\right]$ & 66.8700 & 70.9771 \\
\hline Helical motion velocity coeff [mm/rad] & 11.5478 & 0.0000 \\
\hline
\end{tabular}
helical method. The design parameters for the facemilled hypoid gear set are listed in Table 1. The basic machine settings are listed in Table 2.

Table 1. Design data

\begin{tabular}{lcc}
\hline Design features & Pinion & Gear \\
\hline Number of teeth & 7 & 43 \\
\hline Module [mm] & & 6.861 \\
\hline Face width [mm] & 43.73 & 40.00 \\
\hline Pinion offset [mm] & 25.4 & \\
\hline Shaft angle [ ${ }^{\circ}$ ] & 90 & \\
\hline Mean spiral angle [ ${ }^{\circ}$ ] & 45 & 33.75 \\
\hline Hand of spiral & LH & RH \\
\hline Cutter radius [mm] & 114.3543 & 114.3 \\
\hline
\end{tabular}

Table 2. Basic machine settings for the duplex helical method

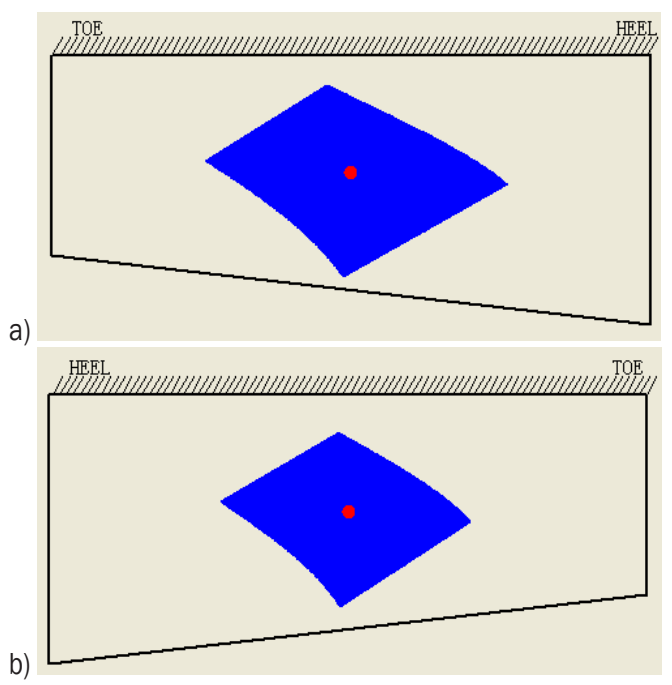

Fig. 6. Tooth bearings for the hypoid gear drive $7 \times 43$; a) drive side, and b) coast side

Figs. 6 and 7 show the tooth bearings and the transmission error functions on the drive and coast side by the duplex helical method for the hypoid gear 
drive $7 \times 43$ (number of pinion teeth $\times$ number of gear teeth), respectively. In Fig. 6, the red point is the first contact point or reference point. It is obsevered that a continuous and negative function is obtained for transmission errors, with a maximum level on the drive side for the method of approximately $15.5^{\prime \prime}$ $\left(0.004306^{\circ}\right)$, and on the coast side of approximately $15.9^{\prime \prime}\left(0.004417^{\circ}\right)$.

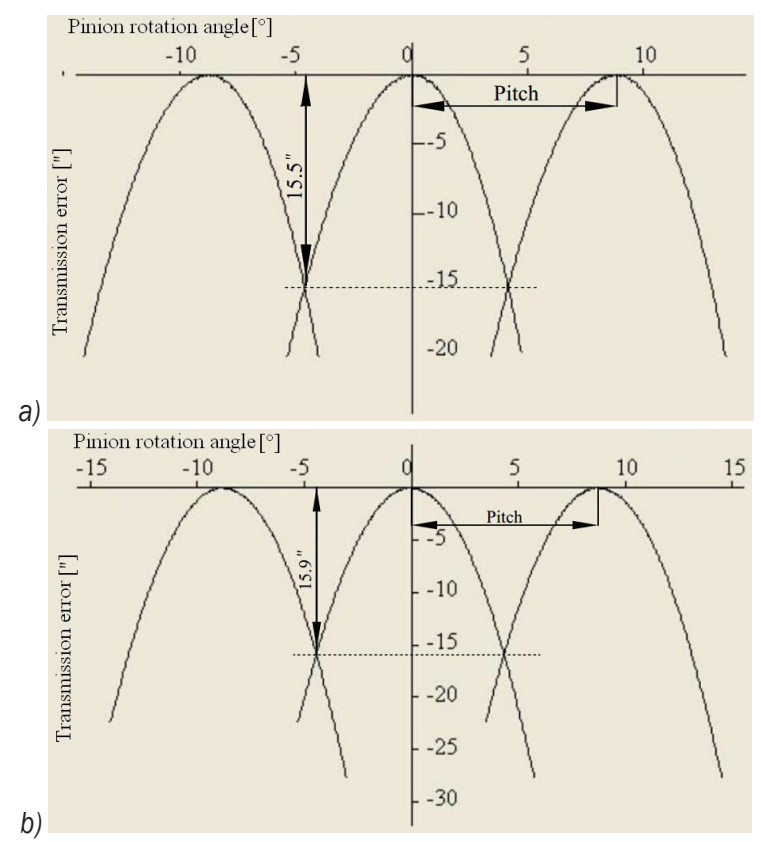

Fig. 7. Function of transmission errors for the hypoid gear drive $7 \times 43$; a) drive side, and b) coast side

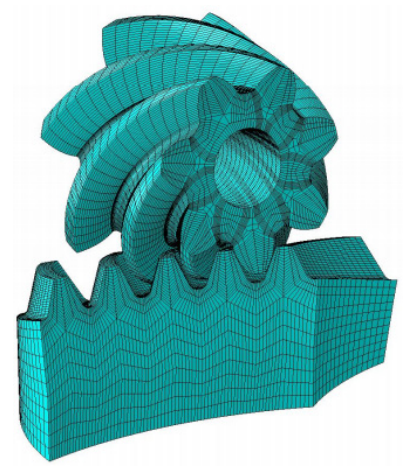

Fig. 8. Finite element model for the hypoid gear drive $7 \times 43$

The load history, especially the transfer of load between neighbouring gear pairs, is very helpful for understanding the gear mesh characteristics. Fig. 8 shows a finite element mesh; five teeth of the gear are used to save costs. Fig. 9 show the evolution of contact stresses of the pinion and gear by the method for the hypoid gear drive. The torque and the rotational speed applied to the pinion are $500 \mathrm{Nm}$ and $1000 \mathrm{r} / \mathrm{min}$, respectively.

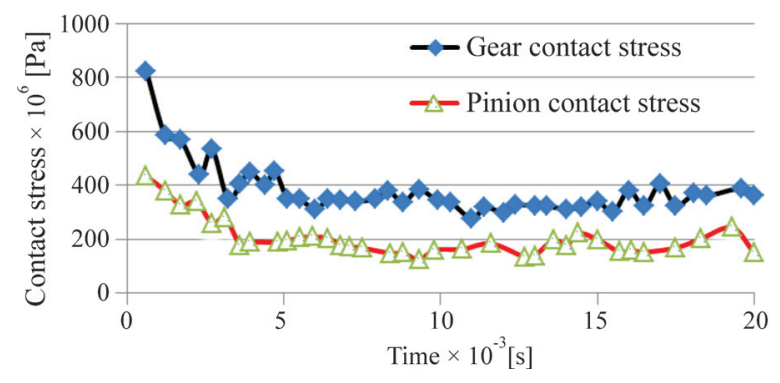

Fig. 9. Evolution of contact stresses for the hypoid gear drive $7 \times 43$
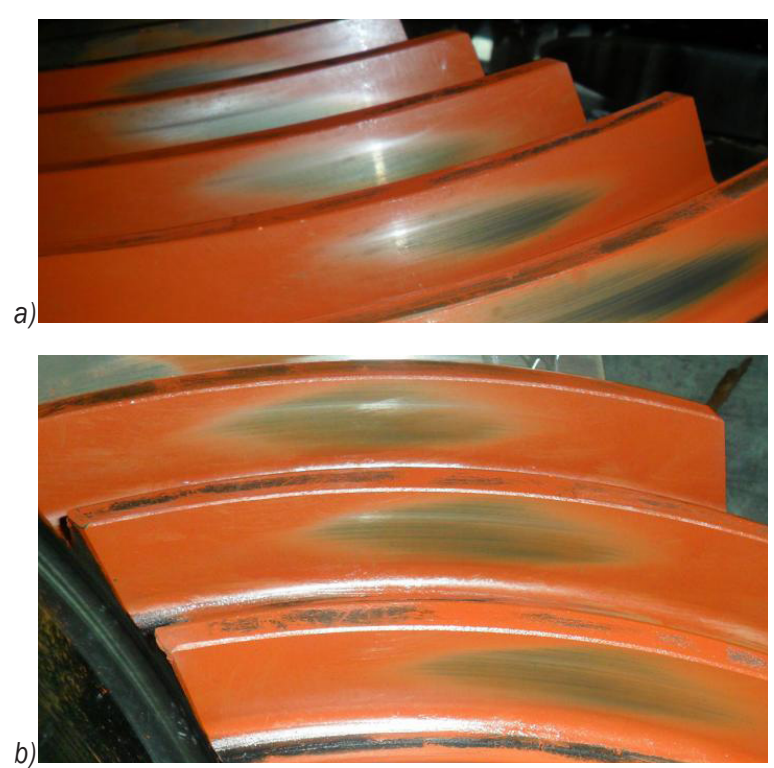

Fig. 10. Tooth bearings on the hypoid gear test machine for the hypoid gear drive $7 \times 43$; a) drive side, and b) coast side

The analysis of the comparison of contact stress evolution is as follows:

(1) There is higher contact stress due to impact in the initial phase; with the smoothing of the rotational speed, contact stress is gradually stabilizing in Fig. 9.

(2) The maximum gear tooth contact stress for the hypoid gear drive is about $300 \mathrm{MPa}$ to $400 \mathrm{MPa}$; the maximum pinion tooth contact stress is about $150 \mathrm{MPa}$ to $200 \mathrm{MPa}$ after $4.5 \mathrm{~ms}$. There is no problem of the appearance of areas of severe contact stress and edge contact throughout the process.

To verify the effectiveness of the generalized theory of the duplex helical method, the cutting and the rolling test experiments are done. Fig. 10 shows the tooth bearings on the hypoid gear test machine for the 
hypoid gear drive $7 \times 43$ by the duplex helical method. The results of the rolling test and the results of TCA in Fig. 6 are carried out under light load. The shape and location of the tooth bearings in Fig. 10 are basically consistent with those in Fig. 6. The experiment results achieve the desired effect. Finally, all of the results proved the correctness of the generalized theory of the duplex helical method described in this paper.

\section{CONCLUSIONS}

The duplex helical method is an advanced and primary manufacturing method of face-milled spiral bevel and hypoid gears. It is a completing process in which the concave and convex tooth surfaces are generated simultaneously under a single set of machine settings, and it is diffcult to obtain a set of optimal machine settings that can ensure both sides of TCA with good characteristics. To slove the problem, some valid conclusions are obtained through this investigation:

(1) A general calculation method of the basic machine settings for all spiral bevel and hypoid cutting methods, including face-milling and facehobbing, is proposed.

(2) Three reference points $\left(\mathrm{M}_{1}, \mathrm{M}_{2}, \mathrm{P}\right)$ are used to calculate basic machine-tool settings for formating hypoid gears manufactured by the duplex helical method; they can accurately control the position and movement relationships between the generating gear and pinion.

(3) The TCA and rolling test experiment results of the hypoid gear set manufactured by the duplex helical method show that the new methodology for calculating the basic machine settings achieves the desired effect. Both sides of TCA results have good characteristics.

\section{NOMENCLATURE}

$\Sigma \quad$ shaft angle $\left[^{\circ}\right]$

$E$ pinion offset (mm)

$\gamma_{m 2}$ machine root angle of gear $\left[{ }^{\circ}\right]$

$X_{G}$ machine centre to back of gear [mm]

$H$ horizontal setting of gear head-cutter [mm]

$V \quad$ vertical setting of gear head-cutter $(\mathrm{mm})$

$q_{2}$ cradle angle of gear $\left[{ }^{\circ}\right]$

$S_{r 2}$ radial distance of gear [mm]

$\alpha_{21}$ inside blade pressure angle (drive side or convex side) for gear $\left[{ }^{\circ}\right]$

$\alpha$ outside blade pressure angle (drive side or concave side) for pinion $\left[^{\circ}\right]$

$\alpha_{12}$ inside blade pressure angle (coast side or convex side) for pinion $\left[^{\circ}\right]$ $\beta_{02}$ spiral angle of the gear generating surface $\left[^{\circ}\right]$

$r_{c G 1}$ cutter point radius for the convex side of the gear [mm]

$\triangle A$ the first induced normal curvature of two conjugate tooth surfaces $\left(\Sigma_{2}\right.$ and $\left.\Sigma_{1}\right)$ at $\mathrm{M}_{1}$

$\Delta B$ the first induced normal torsion of two conjugate tooth surfaces $\left(\Sigma_{2}\right.$ and $\left.\Sigma_{1}\right)$ at $\mathrm{M}_{1}$

$\Delta C$ the second induced normal curvature of two conjugate tooth surfaces $\left(\Sigma_{2}\right.$ and $\left.\Sigma_{1}\right)$ at $\mathrm{M}_{1}$

$\alpha_{G 1}$ pressure angle of drive side of pinion-generating surface [ ${ }^{\circ}$ ]

$H_{p}$ horizontal setting for pinion head-cutter [mm]

$V_{p} \quad$ vertical setting for pinion head-cutter [mm]

$E_{m 1}$ blank offset for the pinion [mm]

$X_{p}$ machine centre to back for pinion [mm]

$X_{b 1}$ sliding base for pinion [mm]

$\gamma_{n 1}$ machine root angle for pinion $\left[{ }^{\circ}\right]$

$S_{r 1}$ radial distance for pinion head-cutter [mm]

$q_{1}$ cradle angle for pinion $\left[^{\circ}\right]$

$I_{1} \quad$ tilt angle for pinion head-cutter $\left[{ }^{\circ}\right]$

$J_{1} \quad$ swivel angle for pinion head-cutter [ $\left.{ }^{\circ}\right]$

$R_{a 1}$ ratio-of-roll of pinion and generating gear

$H_{l}$ helical motion velocity coefficient represents a displacement of the pinion blank along the axis of the cradle for a rotational angle of 1 radian of the cradle $[\mathrm{mm} / \mathrm{rad}]$

$r_{n 1}$ curvature radius of the outside blade of the pinion head-cutter (drive side or concave side) [mm]

$r_{n 2}$ curvature radius of the inside blade of the pinion head-cutter (coast side or convex side) [mm]
Subscripts
1 pinion
2 gear
$G$ generating surface of gear
$p$ genarating surface of pinion
$d r$ drive side
co coast side

\section{ACKNOWLEDGEMENTS}

The authors express their deep gratitude to the National Natural Science Foundation of China (NSFC) (No. 51575533), National Key Basic Research Program of China (973 Program) (NKBRP) (No. 2011CB706800-G), Specialized Research Fund for the Doctoral Program of Higher Education (SRFDP) (No. 20120162110004) and National Natural Science Foundation of China (NSFC) (No. 51375159) for the financial support of the research. 


\section{REFERENCES}

[1] Stadtfeld, H. (2011). Tribology aspects in angular transmission systems part IV: spiral bevel gears. Gear Technology, no. January/February, p. 66-72.

[2] Stadtfeld, H. (2011). Tribology aspects in angular transmission systems part VII: hypoid gears. Gear Technology, no. June/July, p. 66-72.

[3] Fan, Q., Wilcox, L. (2007). New developments in tooth contact analysis (TCA) and loaded TCA for spiral bevel and hypoid gear drives. Gear Technology, no. May, p. 26-35.

[4] Fan, Q. (2006). Computerized modeling and simulation of spiral bevel and hypoid gears manufactured by gleason face hobbing process. ASME Journal of Mechanical Design, vol. 128 , no. 6, p. 1315-1327, Dol:10.1115/1.2337316.

[5] Gleason Works (2004). Applied gear engineering - CAGEWin software customer/dealer tranining center. The Gleason Works, Rochester.

[6] Gleason Works (1971). Calculation instructions generated hypoid gears duplex helical method. The Gleason Works, New York.

[7] Fan, Q. (2011). Optimization of face cone element for spiral bevel and hypoid gears. Journal of Mechanical Design, Transactions of the ASME, vol. 133, no. 9, p. 091002-091001091002-091007, DOI:10.1115/1.4004546.

[8] Zhang, Y., Litvin, F.L. (1995). Computerized design of lownoise face-milled spiral bevel gears. Mechanism Machine Theory, vol. 30, no. 8, p. 1171-1178, D0l:10.1016/0094114X(95)00052-Z.

[9] Wang, J., Kong, L., Liu, B., Hu, X., Yu, X., Kong, W. (2014). The mathematical model of spiral bevel gears - A review. Strojniški vestnik - Journal of Mechanical Engineering, vol. 60, no. 2, p. 93-105, D0l:10.5545/sv-jme.2013.1357.

[10] Shtipelman, B.A. (1978). Design and Manufacture of Hypoid Gears. A Wiley-Interscience Publication, New York.

[11] Fuentes, A., Gonzalez-Perez, I., Litvin, F.L., Hayasaka, K., Yukishima, K. (2007). Determination of basic machine-tool settings for generation of spiral bevel gears from blank data. Proceedings of the ASME International Design Engineering Technical Conferences and Computers and Information in Engineering Conference, p. 57-68, D0l:10.1115/detc200734038.

[12] Litvin, F.L., Zhang, Y., Lundy, M., Heine, C. (1988). Determination of settings of a tilted head cutter for generation of hypoid and spiral bevel gears. ASME Journal of Mechanisms, Transmissions, and Automation in Design, vol. 110, no. 4, p. 495-500, D0l:10.1115/1.3258950.

[13] Litvin, F.L., Fuentes, A. (2004). Gear geometry and Applied Theory (2nd edition). Cambridge University Press, New York, DOI:10.1017/СВ09780511547126.

[14] Astoul, J., Mermoz, E., Sartor, M., Linares, J.M., Bernard, A. (2014). New methodology to reduce the transmission error of the spiral bevel gears. CIRP Annals - Manufacturing Technology, vol. 63, no. 1, p. 165-168, Dol:10.1016/j. cirp.2014.03.124.

[15] Cao, X.M., Fang, Z.D., Xu, H., Su, J.Z. (2008). Design of pinion machine tool-settings for spiral bevel gears by controlling contact path and transmission errors. Chinese Journal of Aeronautics, vol. 21, no. 2, p. 179-186, D0l:10.1016/S10009361(08)60023-0.

[16] Su, J.Z., Fang, Z.D., Cai, X.W. (2013). Design and analysis of spiral bevel gears with seventh-order function of transmission error. Chinese Journal of Aeronautics, vol. 26, no. 5, p. 13101316, DOI:10.1016/j.cja.2013.07.012.

[17] Sobolewski, B., Marciniec, A. (2013). Method of spiral bevel gear tooth contact analysis performed in CAD environment. Aircraft Engineering and Aerospace Technology, vol. 85, no. 6 , p. 467-474, DOI:10.1108/AEAT-11-2012-0207.

[18] Litvin, F.L., Fuentes, A., Hayasaka, K. (2006). Design, manufacture, stress analysis, and experimental tests of low-noise high endurance spiral bevel gears. Mechanism and Machine Theory, vol. 41, p. 83-118, D0l:10.1016/j. mechmachtheory.2005.03.001.

[19] Lin, C.H., Fong, Z.H. (2015). Numerical tooth contact analysis of a bevel gear set by using measured tooth geometry data. Mechanism and Machine Theory, vol. 84, p. 1-24, DOI:10.1016/j.mechmachtheory.2014.09.010.

[20] Fan, Q. (2007). Enhanced algorithms of contact simulation for hypoid gear drives produced by face-milling and face-hobbing processes. ASME Journal of Mechanical Design, vol. 129, no. 1, p. 31-37, DOl:10.1115/1.2359475.

[21] Simon, V. (2007). Computer simulation of tooth contact analysis of mismatched spiral bevel gears. Mechanism and Machine Theory, vol. 42, no. 3, p. 365-381, D0l:10.1016/j. mechmachtheory.2006.02.010.

[22] Tamizharasan, T., Senthil Kumar, N. (2012). Optimization of cutting insert geometry using DEFORM-3D: Numerical simulation and experimental validation. International Journal of Simulation Modelling, vol. 11, no. 2, p. 65-75, D0l:10.2507/ IJSIMM11(2)1.200.

[23] Gonzalez-Perez, I., Fuentes, A., Hayasaka, K. (2011). Computerized design and tooth contact analysis of spiral bevel gears generated by the duplex helical method. ASME International Design Engineering Technical Conferences and Computers and Information in Engineering Conference, $\mathrm{p}$. 149-158, D0l:10.1115/detc2011-47108.

[24] Fong, Z.H. (2000). Mathematical model of universal hypoid generator with supplemental kinematic flank correction motions. ASME Journal of Mechanical Design, vol. 122, no. 3, p. 136-142, Dol:10.1115/1.533552.

[25] Baxter, M.L. (1973). Second-order surface generation. Industrial Mathematics, vol. 23, no. 2, p. 85-106. 